\title{
El cine como pasador de lo real
}

\author{
L'envahisseur | Nicolas Provost | Bélgica 2011 \\ Eduardo Laso* y Juan Jorge Michel Fariña*** \\ Universidad de Buenos Aires
}

Recepción: 15 de diciembre de 2019; aceptación: 2 de febrero de 2020

\begin{abstract}
Resumen
El cine permite dar palabras e imágenes al acontecimiento catastrófico. Ofrece la posibilidad de operar con el real traumático social y en consecuencia simbolizarlo. Tanto el psicoanálisis como el arte emprenden, por vías distintas, esta ardua tarea de hacer pasar lo real a lo simbólico, de inscribir lo imposible. Se trata de dar imágenes, palabras y representaciones a aquello que en principio está ausente, silenciado, rechazado. Para que ese real deje de ser una mortificación hecha herida abierta, instalada como repetición vana. En ese sentido, el cine es pasador de lo real a lo simbólico a través de las imágenes. El presente artículo introduce esta tesis a través de ejemplos de la pintura, la performance y el cine.
\end{abstract}

Palabras clave: Cine | Proceso creador | Psicoanálisis |Trauma

\begin{abstract}
Cinema allows words and images to be given to the catastrophic event. It offers the possibility of operating with the real traumatic and consequently symbolizing it. Both psychoanalysis and art undertake, through different routes, this arduous task of passing the real to the symbolic, of inscribing the impossible. It is about giving images, words and representations to what is initially absent, silenced, rejected. So that this real ceases to be a mortification made open wound, installed as a vain repetition. In this sense, cinema is a passer from the real to the symbolic through images. This article introduces this thesis through examples from painting, performance and cinema.
\end{abstract}

Keywords: Cinema | Creative process | Psychoanalysis | Trauma

La imponente belleza de la modelo Hannelore Knuts divide la pantalla entre la muerte y la vida.

Elaborar un trauma -individual o colectivo- supone el trabajo arduo de simbolizar un exceso situacional que ha arrasado al sujeto y a la Polis, con el objeto de hacer pasar ese real al campo de lo representable. El siglo XX podría pensarse como un siglo pletórico en acontecimientos desastrosos. Algunos autores llaman al siglo XX el "siglo de los genocidios". Basta recordar los más emblemáticos: el genocidio armenio, el Holodomor en Ucrania, la Shoah, el genocidio indonesio, el genocidio camboyano, el genocidio ruandés, los terrorismos de estado en Latinoamérica. Frente a estas catástrofes de la humanidad, ¿cómo simbolizar lo real traumático, cuando éste se presenta bajo la forma del goce mortificante del semejante? ¿Cuándo ese mal se abisma en el insondable goce del otro? ¿En lo que el hombre le hace al hombre?
Tanto el psicoanálisis como el arte emprenden, por vías distintas, la ardua tarea de hacer pasar lo real a lo simbólico, de inscribir lo imposible. De dar imágenes, palabras y representaciones a aquello que en principio está ausente, silenciado, rechazado, a la espera de ser reconocido, para que deje de ser una mortificación hecha herida abierta, instalada como repetición vana. Sea aquel acontecimiento que por ser arrasador sitúa un intolerable imposible de ser mostrado, visto u oído (por ej. los campos de concentración), sea el redoblamiento de ese imposible de simbolizar en la prohibición de simbolizar tan cara a los Creontes de este mundo: Turquía frente al genocidio armenio, los negacionistas del Holocausto, los legitimadores de los Gulags en nombre de la Revolución, o los asesinos de uniforme del Proceso de Reconstrucción Nacional en Argentina. 


\section{¿Qué es lo Real?}

Ya desde el inicio de su enseñanza, Lacan (1953) distinguió tres registros que fue desarrollando y enriqueciendo: Real, Simbólico e Imaginario, enlazados al modo de nudo borromeo (si uno se desanuda, los otros también; no hay modo de pensarlos como registros puros y separados) en los que se desenvuelve la subjetividad.

Lo real no se confunde con la realidad (que es un entramado de simbólico e imaginario), siendo caracterizado por Lacan a lo largo de sus seminarios como:

- Aquello que escapa o ex-siste a lo simbólico e imaginario

- Lo que vuelve siempre al mismo lugar (con lo cual enlaza lo real a la compulsión a la repetición freudiana)

- Lo imposible lógico

- Lo que no cesa de no inscribirse

Lo real para el psicoanálisis no tiene que ver con una categoría filosófica al modo del noúmeno kantiano. Lo real es agujero producido por la entrada del orden simbólico en el viviente humano. El significante introduce la falta en el parlêtre, una pérdida de goce que causa a desear y a hablar. Freud llamó a esa falta fundante de la subjetividad Das Ding. En su Proyecto de una psicología para neurólogos la introduce al hablar del complejo del semejante: en la relación del niño con la madre, una parte de ella queda integrada en el sistema de representaciones del niño, haciendo del Otro materno algo familiar, reconocible, ligado al sentido y al principio del placer. Pero hay otro aspecto que escapa a toda representación y sentido, permaneciendo como Cosa innombrable, inasimilable. Vacío inquietante que se aloja en el sistema de representaciones como excluido de toda representación. Este vacío -que hace al misterio de aquel objeto que operaría como causa última del deseo del Otro primordial-, convoca al niño a que lo colme, haciéndose objeto. La Cosa innombrable, irrepresentable y sin sentido opera como un vacío que empuja al sujeto más allá del principio del placer, en el esfuerzo de cancelar la falta del Otro. Freud llamará pulsión de muerte a ese empuje mortificante que como compulsión de repetición apunta a la imposible cancelación de la falta primordial. De ahí la paradoja ética que encierra la relación del sujeto con el goce en tanto empuje hacia aquello que en la vida puede preferir la muerte.

El complejo de Edipo, la metáfora paterna y la operación de castración permiten sacar al sujeto de la trampa de pretender colmar la falta del Otro materno, para nacer como sujeto de deseo. La castración materna ligada a la lógica fálica oficia de función de nudo imaginario y simbólico de la diferencia sexual real. El vacío pasa a significarse como falta sexual. Inscripta a cuenta del sujeto la falta en el Otro, el horror a la castración materna y al empuje a colmar la falta como pulsión de muerte signan los destinos del sujeto de deseo y sus avatares fantasmáticos.

Lo real, si bien excede a lo imaginario y lo simbólico, no por ello carece de modos de hacérsele presente al sujeto: en la forclusión -cuando algo rechazado de lo simbólico retorna en lo imaginario en forma de alucinaciones-, en la experiencia de lo siniestro, en el costado gozoso del síntoma, o como objeto causa de deseo del sujeto y plus de goce en el fantasma. La muerte de un ser amado o un acontecimiento catastrófico también operan como un real para el sujeto, sorprendido por un exceso para las que no estaba preparado que lo traumatiza, remitiéndolo a la situación de desamparo primordial y la falta del Otro.

Lo real como lo imposible de simbolizar, implica para el sujeto la exigencia de simbolización, en el intento de hacer pasar lo real al registro lo simbólico. En esta tarea de hacer pasar lo real a su inscripción, y por vías diferentes, el trabajo del análisis y la creación estética cruzan sus caminos.

\section{La belleza del objeto estético como pasadora de lo real}

"Habia llegado a ese punto de emoción en el que se encuentran las sensaciones celestes dadas por las Bellas Artes y los sentimientos apasionados. Saliendo de Santa Croce, me latía el corazón, la vida estaba agotada en mí, andaba con miedo a caerme". Así describía Stendhal en su libro Nápoles y Florencia: un viaje de Milán a Reggio, sus vivencias luego de visitar en 1817 la basílica de la Santa Cruz en Florencia. Estupor, vértigo, confusión, palpitaciones, son las respuestas sintomáticas del escritor a su confrontación con un exceso sublime de belleza. Como era de esperar, la psiquiatría terminó encontrando un nombre para este síndrome: en 1979 la psiquiatra italiana Graziella Magherini lo bautizó "síndrome de Stendhal" y lo ubicó dentro de las enfermedades psicosomáticas, como una reacción causada por la exposición a obras de arte especialmente bellas. Sólo faltó explicar por qué la exuberancia de belleza puede provocar semejante respuesta en un sujeto. 
Que la obra de arte sea capaz de suscitar por su belleza este efecto perturbador es un indicador de que la dimensión de lo real ha sido evocada. El poeta Rainer Maria Rilke decía que lo bello "es el comienzo de lo terrible que todavía podemos soportar" ${ }^{1}$. Y en esa misma línea, Lacan planteaba a lo bello como la última barrera ante lo real de la Cosa innombrable. Se trata, al fin y al cabo, de la relación de la belleza a un real inquietante. Y de la obra de arte como pasadora de un real insimbolizable.

La obra de arte encierra la paradoja de ser un objeto de la percepción que sin embargo transmite algo que va más allá de lo sensible. Al hacerlo, interpela al sujeto, al darle acceso a una experiencia de goce por la que queda fascinado pero de la que ignora su causa. Atrapante pero enigmática, la obra se muestra opaca e inaccesible, al tiempo que nos implica al evocarnos un más allá que expresa mediante formas, sonidos, palabras o movimientos. Eso evocado concierne a lo real en el sentido planteado por Lacan como lo imposible de ser simbolizado o plasmado en imágenes.

La creación artística es un modo de enfrentar el horror a la castración y elaborar lo real traumático mediante el recurso a lo bello. Tanto Freud como Lacan vinculan la creación artística a la sublimación. Lacan la definía como la elevación de un objeto a la dignidad de la Cosa. Si el significante introduce la pérdida de goce que causa a desear, la sublimación en tanto creación ex nibilo repite la operación fundante de la subjetividad: engendra a partir de la nada, en el intento de representar lo irrepresentable.

La obra de arte se construye en torno de un vacío: la página en blanco del escritor, la tela del pintor, el espacio del arquitecto, lo informe de la piedra o la masilla del escultor, o el silencio sobre el que el músico evocará la "nota azul". ${ }^{2}$ Y si por el contrario la obra no evocara esa dimensión de lo real tras el velo, cumpliría una función renegatoria cual un fetiche. Sería un arte falso, arte de consumo, o arte al servicio de la ideología imperante.

\section{El travelling de L'envahisseur ${ }^{3}$}

El cine, cuando no está al servicio de promover un fetichismo de la imagen, se presta a la empresa de dar palabras e imágenes al acontecimiento catastrófico que opera como real traumático social y así simbolizarlo. Condición de posibilidad para hacerlo entrar también en un orden legal. Un ejemplo elocuente es el film belga L'envabisseur en torno de la inmigración ilegal y la segregación.
El inicio de El invasor, de Nicolas Provost, es un largo travelling que comienza con el enigmático primer plano de un sexo femenino. Se trata de una cita al célebre y escandaloso cuadro El origen del mundo. En 1866 Gustave Courbet pintó un óleo sobre lienzo de 55×46 $\mathrm{cm}$ para el millonario y diplomático turco Khalil Bey. El cuadro muestra el pubis, las piernas abiertas y parte del vientre de una mujer acostada sobre una sábana blanca. Nunca antes se había representado en el arte pictórico al sexo femenino de modo tan realista. Mucho menos como centro excluyente de un cuadro.

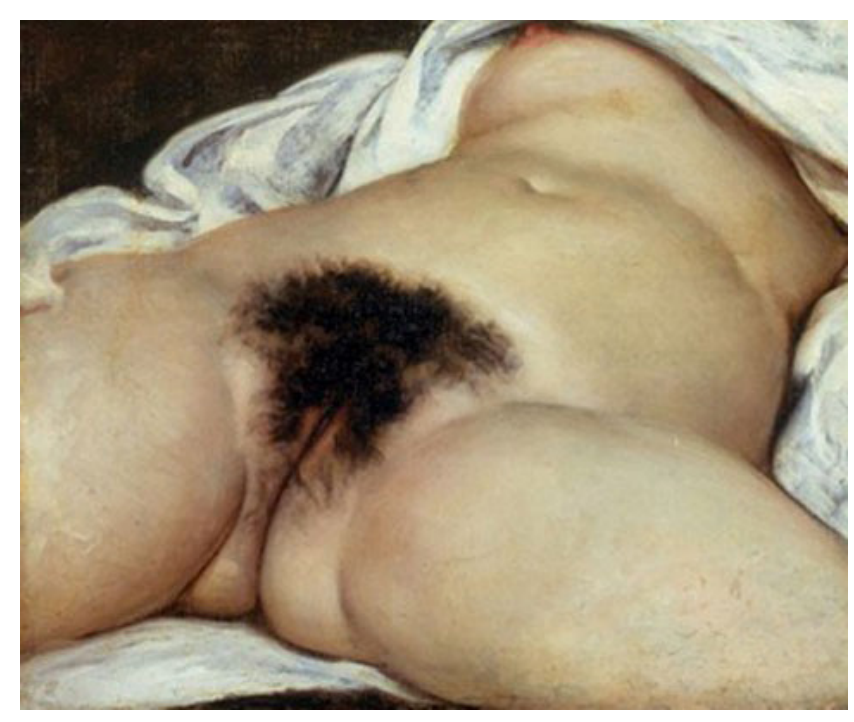

El origen del mundo, Gustave Courbet (1866)

Si bien Courbet no la nombró así, la obra se hizo conocida como "El origen del mundo". Luego de la muerte de Khalil Bey, el cuadro pasó por varias colecciones privadas. El anticuario Antoine de Narde la compró en un remate y por pudor prefirió cubrirla con otro cuadro de Courbet, el paisaje "La casa de Blonay". En 1913, los dos cuadros, siempre uno cubriendo al otro, se expusieron en la Galería Bernehim-Jeune, de París, sin que se conociera su propietario. El conde Ferencz Hatvany, pintor y coleccionista, exponía en esa galería y decidió comprar todos los cuadros de Courbet. Los llevó a Hungría y procedió como todos los propietarios anteriores de " $E l$ origen del mundo": lo mantuvo oculto bajo solapado bajo otro cuadro. Los alemanes invadieron Hungría y, como lo hicieron en toda Europa, se robaron las obras de arte. La obra de Courbet corrió esa triste suerte. Con el final de la guerra, los soviéticos la recuperaron y la devolvieron a la familia Hatvany. El conde se trasladó a París y, en 1955, le vendió el cuadro a Jacques Lacan por un millón y medio de francos. Cuando Lacan muere 
en 1981, el estado francés embargó algunos de sus bienes debido a deudas impagas. Es así como El origen del mundo pasó a formar parte del Museo de D’Orsay hasta la actualidad.

La imagen del sexo femenino dispuesta en un entorno que sugiere el acto sexual, suscitando la atracción de la mirada, resultó escandalosa en su momento y todavía hoy conserva su poder perturbador. El nombre El origen del mundo que Courbet no eligió, asocia la imagen del sexo femenino al lugar del que los humanos salimos al nacer. Lo que agrega un sentido materno a la inquietante representación. La visión ofrecida ya no sería meramente del sexo femenino, sino de la castración materna, con la mezcla de fascinación y horror que suscita su visión. ${ }^{4} \mathrm{El}$ título desplaza el tema erótico hacia la falta del Otro materno, ante cuya visión el niño y la niña se encuentran divididos. Amenaza de castración o castración realizada, la falta de falo materno encarna la visión de la cabeza de Medusa de los mitos griegos. ${ }^{5}$

Cien años después, Marcel Duchamp concluyó su última gran obra, en la que trabajó durante 20 años (19461966). Étant donnés, la primera instalación de la historia del arte, vuelve sobre el tema de la pintura de Courbet: a través de unas mirillas en una puerta de madera, se puede ver por el boquete de una pared al cuerpo de una mujer desnuda con las piernas abiertas mostrando su sexo rasurado, sosteniendo en una mano una lámpara de gas contra el fondo de un paisaje bucólico. Otra vez el sexo femenino aparece en el centro de la representación, como en el cuadro de Courbet.

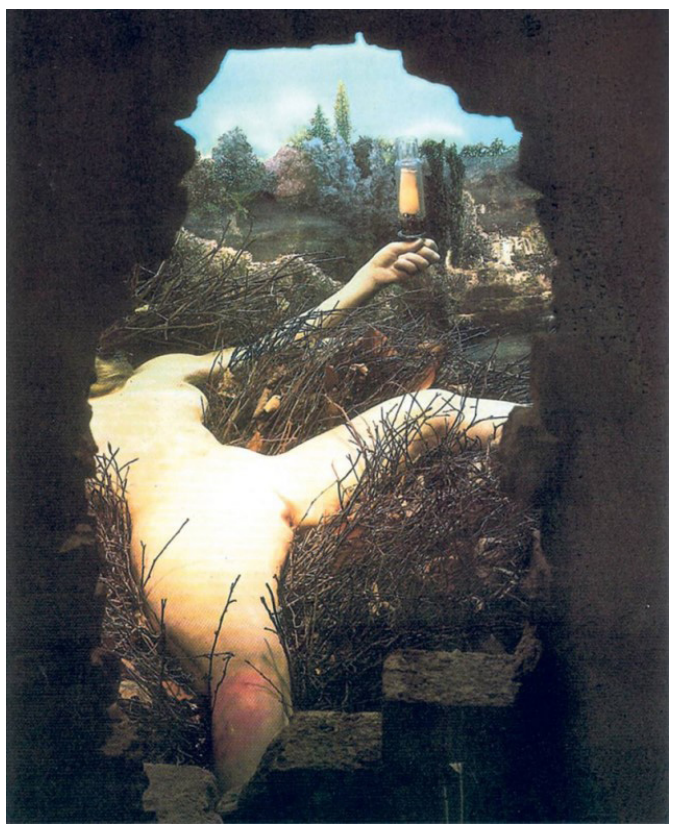

Étant donnés, Marcel Duchamp, (1966)
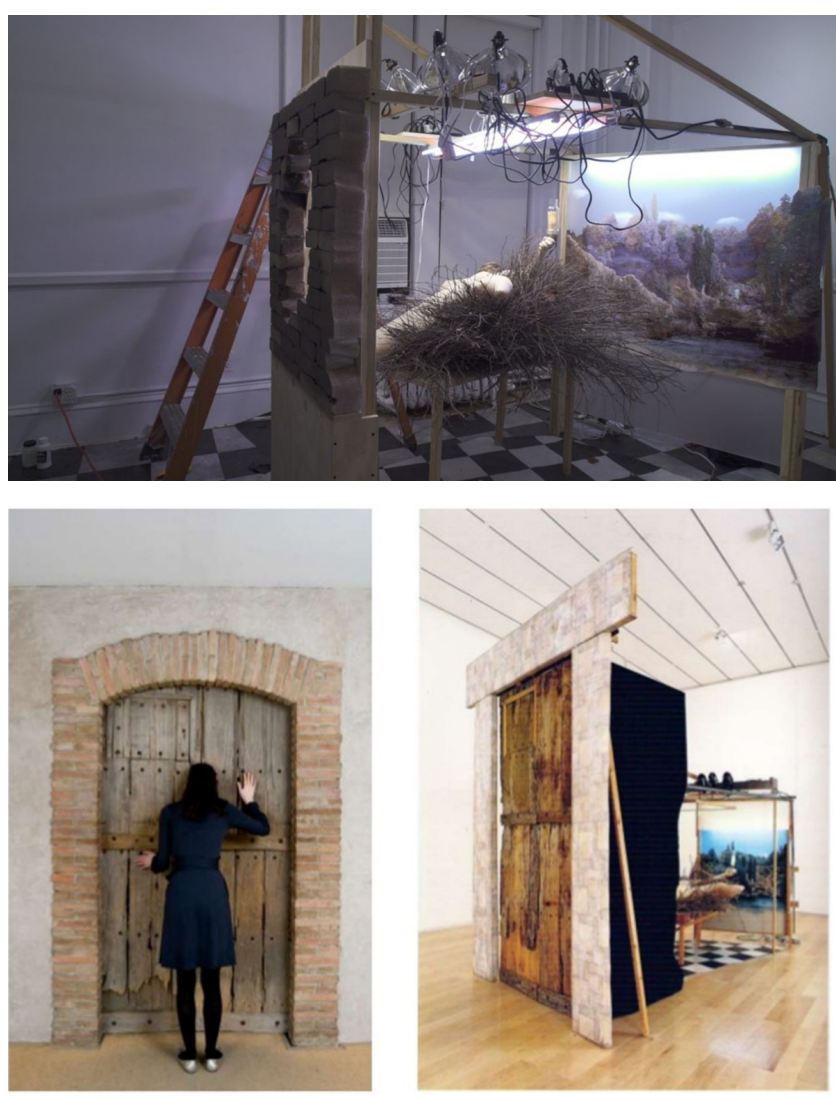

Detalles de la instalación Étant donnés, Marcel Duchamp, (1966)

Y si El invasor homenajea a El Origen del Mundo, el film de Bruno Dumont L'bumanité homenajea a Étant donnés, al hacer un primer plano del sexo femenino de una jovencita asesinada en la campiña francesa. ${ }^{6}$

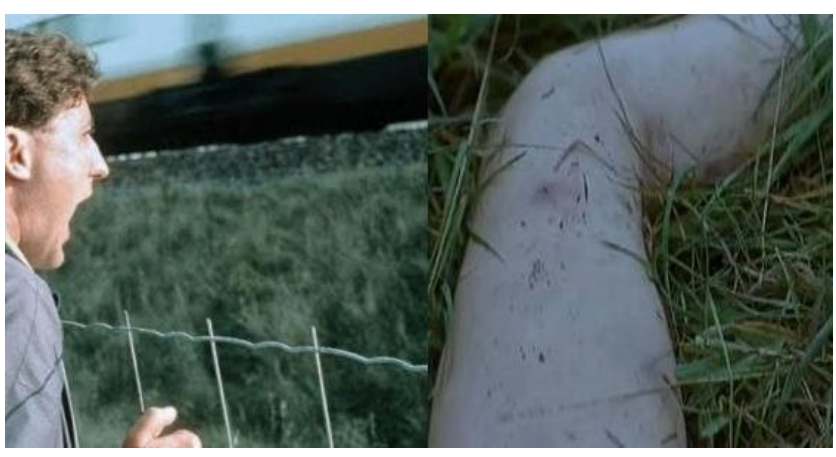

El policía descubre el cadáver de una joven.

L'humanité, de Bruno Dumont (1999)

En el travelling de L'envabisseur no nos encontramos en el estudio de Courbet. La cámara de Probost parte del sexo desnudo de una mujer y de allí se va alejando para ir de a poco ofreciéndonos información sobre la escena. El cuerpo es de una joven que está tomando sol en una playa. La vemos incorporarse y mirar hacia un punto a la distancia. La joven, de cuerpo blanco e imponente, se 
levanta y empieza a caminar. Mientras se mueve, advertimos que hay otras personas también desnudas. Estamos en una playa nudista, una de las tantas de las costas de Europa. Vemos la mirada atenta y extrañada de la mujer, dirigida hacia un punto fuera de la escena. Tras ella, varios bañistas corren desesperados hacia el mar. Algo inquietante ha sucedido. Entran entonces en el plano varios cuerpos inertes en la arena y personas que tratan de reanimarlos. Mientras la joven prosigue su caminata, la cámara gira hacia la escena que la atrae. Vemos entonces a dos hombres de raza negra exhaustos, casi desnudos, que con esfuerzo salen del mar. Y entonces advertimos súbitamente el sentido de la secuencia: estamos ante el naufragio de un grupo de africanos que escapó de su país para ingresar clandestinamente en las costas de Europa. Situación no por repetida menos terrible, dado en su pobreza y desesperación se valen de embarcaciones precarias, con el riesgo de morir ahogados en la travesía. Con un movimiento de cámara, Provost consigue un cambio abrupto de registro: de la belleza y el erotismo de la playa, a la muerte de un grupo de náufragos inmigrantes. El horror tras la belleza.

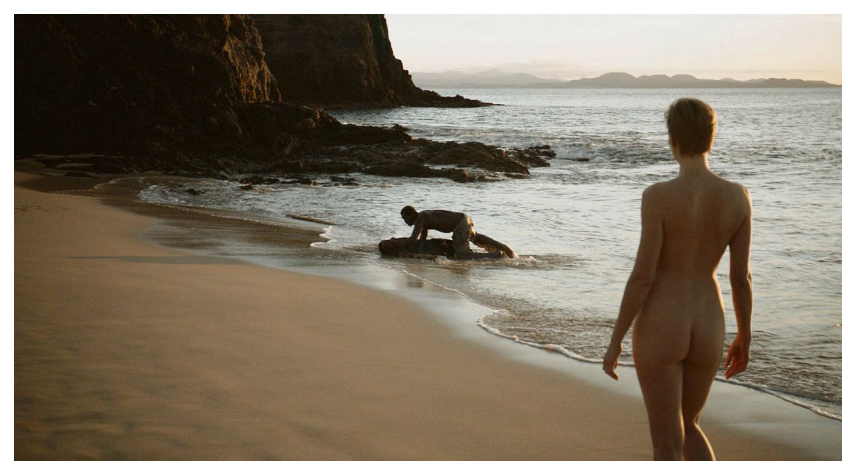

Provost juega con el contraste entre la frívola playa nudista y el siniestro naufragio de unos africanos ilegales. También entre el cuerpo blanco de la mujer europea y los cuerpos negros de los inmigrantes. Pero sobre todo con la ambigüedad del cruce de miradas entre ella y los sobrevivientes. La mujer los mira con altiva extrañeza. Para ella son la encarnación de lo Otro, algo extraño y extranjero que invade su espacio de confort. No hay en ella ninguna mirada de piedad, sino en todo caso de interrogación por la presencia de seres absolutamente ajenos a su entorno. La mirada del africano hacia ella, en cambio, configura una mezcla de tristeza y desesperación, a la vez que estupor y fascinación ante la belleza de la mujer, y vergüenza por cómo es visto por ella. La espléndida mujer encarna para el inmigrante a Europa, el primer mundo, la ilusión de una vida mejor, el objeto de deseo que de alcanzarse, garantizaría la felicidad. Sólo que vistos desde la mirada del europeo, ellos son sólo invasores, extranjeros, o a lo sumo mano de obra explotable. Un objeto deyecto del sistema económico, cuya aparición no es bienvenida.
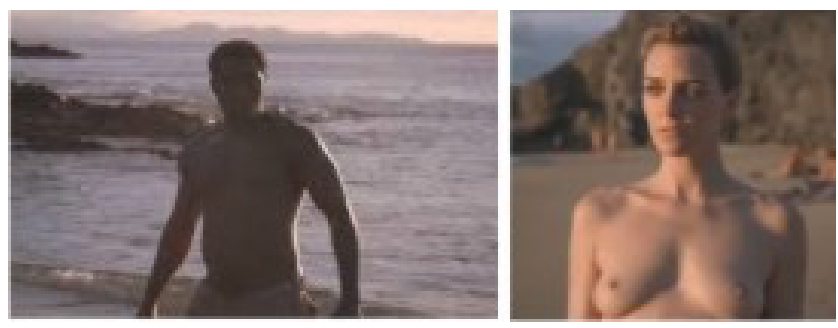

El travelling de Provost muestra la potencia del cine para revelar en un solo plano-secuencia la tragedia de los inmigrantes ilegales y el aspecto inquietante de Europa como tierra de promisión. La cita pictórica a $E l$ origen del mundo de Courbet constituye, por un lado, un comentario irónico a la creencia de los europeos de ser el origen de la cultura. El eurocentrismo considera a Europa como origen del mundo cultural, frente al resto del planeta. Ilusión que convoca al deseo de los excluidos a vivir en sus tierras. Sólo que la identidad europea se soporta sobre la base de la segregación y explotación de lo que no es "europeo", sea lo que sea lo que eso signifique.

Por otro lado, la cita al cuadro ubica a Europa como la Cosa mortífera que se esconde bajo el velo de la belleza clásica encarnada por el cuerpo de la modelo Hannelore Knuts. Ella se presenta al modo de una diosa griega para estos refugiados. Sólo que no sabemos si esta diosa los acogerá en su seno... o los pulverizará con un rayo.

\section{Coda: de la belleza sublime al acting out}

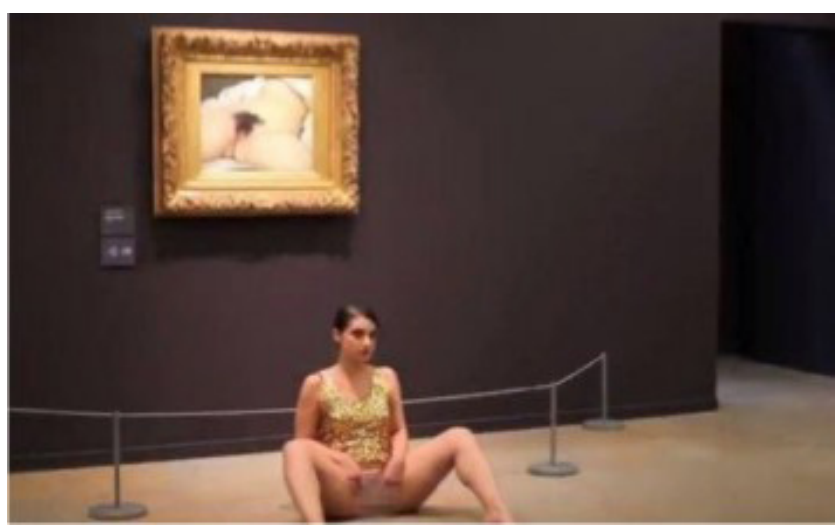

En 2014 la artista luxemburguesa Debora de Robertis ingresó a la sala del museo de Orsay en la que se 
encuentra el cuadro de Gustave Courbet El origen del mundo. Con un vestido corto de lentejuelas doradas y sin ropa interior, De Robertis se sentó ante la famosa obra, abrió las piernas y, con ayuda de sus manos, mostró su sexo a los visitantes durante varios minutos, mientras un colaborador suyo filmaba la escena. Los trabajadores del museo, según se puede ver en el video subido por la artista en internet, se interpusieron entre ella y el público para obstaculizar la visión y, sin forzarla físicamente a interrumpir el espectáculo, procedieron a desalojar la sala. La escena suscitó miradas sorprendidas, pero también aplausos entre los asistentes.

Estamos ante un buen ejemplo de la diferencia entre representación estética y mostración obscena de la cosa misma sin tour sublimatorio de la pulsión. A diferencia de Duchamp, quien se valió de un mingitorio para instalar una pregunta por el arte, de Robertis (mal) entendió que la mostración obscena en un museo bajo el amparo de Courbet, convertiría su gesto exhibicionista en una obra sublime.

\section{Referencias}

Bouchareb, R. y Bréhat, J. (productores) y Dumont, B. (director). (1999). L’humanité [cinta cinematográfica]. Francia.

Bronckart, J.H. y Bronckart, O. (productores) y Provost, N. (director). (2011). L'envabisseur [cinta cinematográfica]. Bélgica.

Freud, S. (1922). La cabeza de Medusa. En Obras Completas, Volumen XVIII,. Buenos Aires: Amorrortu, 1975.

Freud, S. (1927). El fetichismo. En Obras Completas, Volumen XXI. Buenos Aires: Amorrortu, 1975.

Lacan, J. (1953). Le Symbolique, l'Imaginaire et le Réel. En: Bulletin de l'Association freudienne, (1), 1982, pp. 4-13.

Lacan, J. (1959). Seminario 7. La ética del psicoanálisis. Buenos Aires: Paidós.

Mendieta Paz, P. (2014). La nota azul. Recuperado de: https://www.paginasiete.bo/ideas/2014/2/9/nota-azul-13374.html

Trias, E. (2006). Lo bello y lo siniestro. Buenos Aires: Editorial Airel.

\footnotetext{
1 Citado por Eugenio Trías en su obra “Lo bello y lo siniestro", Barcelona, 1970.
}

2 La "nota azul" no es una nota en particular, sino un punto musical que hace escuchar lo inaudito. Cifra sonora de la falta del Otro y modo de repetirla en forma musical, la nota azul logra evocar lo intangible de la ausencia y abrir a un más allá del sentido. La falta, sublimada en música, provoca en el sujeto goce y nostalgia.

Así, cuando el grueso de los oyentes estamos a la escucha de un vibrante blues, de una improvisación de jazz auténticamente inspirada, de una excelsa obra clásica, o de la primaria música de cinco notas, siempre nos sentiremos tocados por el hecho de que el encadenamiento de las notas por las que nos dejamos llevar nos conduce, sin duda posible, hacia un punto fijo, excitable, donde no es exagerado decir que es como el punto de explosión de los sentimientos, como un efecto de golpe adelantado al propio discurso musical que se está escuchando. (Mendieta Paz, 2014, s/d)

El vacío como innombrable e irrepresentable remite al horror a la castración del Otro. Modo de significar el vacío como falta.

En el Seminario La ética del psicoanálisis (1959) Lacan plantea que el objeto artístico es instaurado en cierta relación con La Cosa, destinado al mismo tiempo a delimitarla, presentificarla y ausentificarla. En la sublimación se representa das Ding a través de un objeto que haga presente el vacío como representación de lo irrepresentable. De ahí el carácter paradójico de la obra de arte, al dar imagen a lo inimaginarizable, dar a escuchar lo inaudible, o dar a ver lo invisible. Ella es presencia a una ausencia, haciéndose así pasadora de lo real que escapa al significante y la imagen.

Que el arte logre ser pasador de lo real a lo simbólico por vía de lo imaginario implica la virtud del arte de valerse de recursos sensibles para lograr transmitir algo que la sensibilidad no podría captar de manera directa. Empleamos aquí el término pasador en el sentido de:

- $\quad$ aquello que permite cambiar una cosa de un estado a otro (para el caso, de lo real a lo simbólico)

- lo que permite transmitir o comunicar una propiedad, haciéndola llegar a alguien o a un lugar.

El objeto de arte puede devenir un medio que transmita algo que ya no es un objeto concreto sino un real irrepresentable evocado al sesgo. Al hacerlo, se vuelve "pasador": logra comunicar una dimensión que está más allá de los sentidos. Se vuelve mediador entre un estado irrepresentable y otro representable. Apela a nuestros sentidos pero para hacerlos trascender. Para lo cual el recurso a la belleza resulta esencial. La belleza opera como última barrera ante la Cosa horrorosa e innombrable. Esa barrera es un velo del horror que, al darle alguna forma, permite al mismo tiempo presentirla.

Bajo el velo de la belleza, el horror se hace presente en la obra de arte. Si se descorriera ese velo, caería el efecto estético y la obra erraría el blanco. [[Es lo que pasa con algunas obras de arte contemporáneo que buscan la fealdad, en un esfuerzo ingenuo de retirar el velo de la belleza para enfrentar al espectador a "lo real", como si con ese recurso se lograra representar lo irrepresentable de manera directa. La caída del velo de la belleza destruye el efecto estético, provocando en el sujeto lo contrario de enigma y fascinación. A saber, banalización o rechazo. Como la banana pegada con cinta adhesiva en la galería de la feria de arte Art Basel en Miami (obra de Maurizio Catellan que terminó siendo justamente devorada por un espectador). O la performance de Debora de Robertis ante el cuadro de Courbet El origen del mundo, a la que hacemos referencia en la coda de este artículo. 
3 Nicolas Provost, L'envahisseur, Bélgica, 2011, 95'

$4 \quad$ Freud, S.; El fetichismo (1927), en Obras Completas, Volumen XXI, Buenos Aires, Amorrortu, 1975, pág. 141.

$5 \quad$ Freud, S.; La cabeza de Medusa (1922), en Obras Completas, Volumen XVIII, Buenos Aires, Amorrortu, 1975 , pág. 270.

6 Bruno Dumont, L'bumanité, 1999, Francia, 141'. 